\title{
Focal Segmental Glomerulosclerosis - Does Treatment Work?
}

\section{See Goumenos et al., pp. c75-c82}

\author{
C.M. Stirling \\ Renal Unit, Glasgow Royal Infirmary, Glasgow, UK
}

Focal segmental glomerulosclerosis (FSGS) is a common cause of adult nephrotic syndrome, accounting for between 10 and $35 \%$ of adult cases [1,2]. Historically, the prognosis of untreated nephrotic patients is poor, with $50 \%$ developing end-stage renal failure within 8 years $[3$, 4]. Treatment with prednisolone for $4-8$ weeks had a marginal effect on outcomes. Recent studies have shown that high dose prednisolone for longer periods of $4-5$ months improved response rates from 15 to 67\% [5-7]. However, in current clinical practice, $40-50 \%$ of patients with FSGS and nephrotic range proteinuria are not treated with immunosuppression [7].

The report by Goumenos et al. [8] in this edition of Nephron Clinical Practice adds to the evidence that treatment with immunosuppression can lead to remission of nephrotic range proteinuria in patients with FSGS. Despite its limitations as a retrospective study with a small patient population, it has 5-year follow-up data and reports remission rates of $75 \%$. It also demonstrates that treatment using a combination of lower dose prednisolone and azathioprine or cyclosporine may be an effective alternative to high dose prednisolone alone, particularly in patients in whom avoidance of high dose prednisolone is preferable (those with diabetes, obesity or osteoporosis). Their remission rates are amongst the best recorded in the literature, although we must bear in mind that the numbers in this study are small.

\section{KARGER \\ Fax +41613061234 E-Mail karger@karger.ch} www.karger.com (c) 2006 S. Karger AG, Basel

$1660-2110 / 06 / 1042-0083 \$ 23.50 / 0$

Accessible online at:

www.karger.com/nec
This study also confirms that the mean time to remission in treated FSGS patients can be as long as 5 months and that treatment should continue beyond that time. It reports a relapse rate of $20 \%$ and a spontaneous remission rate of $30.7 \%$. Recent studies have also demonstrated higher spontaneous remission rates than those previously [7], particularly in comparison with American series. The higher spontaneous remission rate in Europe may reflect different disease aetiology, but this could also be due to better blood pressure control or increased use of ACE inhibitors or angiotensin receptor blockers (ARBs). There is evidence that ARBs can reduce proteinuria in patients with FSGS resistant to immunosuppressive treatment [9].

The presence of persistent nephrotic range proteinuria is a consistent indicator of a poor prognosis in FSGS, as it is in other glomerular diseases [10]. Achievement of remission has been shown to be an important prognostic marker [7, 11]. Studies report 94\% 5-year renal survival rates in patients who achieve remission, compared with 53\% 5-year survival rates in patients who do not achieve remission. The Toronto Registry Group also showed in their study that achieving and maintaining partial remission confers long-term benefit. However, there is a relative paucity of randomised control trial evidence in FSGS to guide treatment decisions and many nephrologists appear reluctant to recommend a prolonged course of im- 
munosuppression. One reason for this may be the fear of toxicity of corticosteroids. This has to be weighed against the consequences of remaining nephrotic for a prolonged period, particularly in patients who have additional cardiovascular risk factors. The paper by Goumenos et al. [8] suggests an alternative immunosuppressive regimen, with a lower cumulative dose of steroids. This may be more attractive for certain groups of patients at greater risk of steroid side effects and allow a greater number of patients to be considered for treatment.

There is recent evidence that patients resistant to 'conventional' immunosuppression may respond to newer agents such as tacrolimus [12] or mycophenolate (MMF) [13] with a reduction in proteinuria and stabilising of renal function. Rapamycin and rituximab have shown some promise in small clinical studies but would need to be examined in larger studies before any firm conclusions can be drawn.

The NIH FSGS clinical trial is underway, examining patients aged between 2 and 35 years with steroid-resis- tant FSGS, randomising them to either low dose steroid, ACE/ARB + cyclosporin or low dose steroid, ACE/ARB + MMF. Although this is a younger patient population, it will still inform us about the potential role of MMF in steroid-resistant FSGS.

There is growing evidence for treatment options in patients with FSGS and nephrotic range proteinuria. Patients treated with immunosuppression are more likely to achieve remission and those who achieve remission have a better renal prognosis. Untreated patients have a poor prognosis unless they remit spontaneously. The use of ACE inhibitors or ARBs can reduce proteinuria in patients who are resistant to immunosuppressive therapies and can be a useful adjunct. Our challenge is to develop larger prospective trials that help inform our clinical decision making in this area. In the meantime, our FSGS patients with nephrotic range proteinuria need us to evaluate the evidence of the benefits of immunosuppression to maximise their chances of achieving remission.

\section{References}

1 Haas M, Meehan SM, Karrison TG, Spargo $\mathrm{BH}$ : Changing etiologies of unexplained adult nephrotic syndrome: a comparison of renal biopsy findings from 1976-1979 and 1995-1997. Am J Kidney Dis 1997;30:621631.

2 Schena FP: Survey of the Italian Registry of Renal Biopsies. Frequency of the renal diseases for 7 consecutive years. The Italian Group of Renal Immunopathology. Nephrol Dial Transplant 1997;12:418-426.

3 Korbet SM, Schwartz MM, Lewis EJ: Primary focal segmental glomerulosclerosis: clinical course and response to therapy. Am J Kidney Dis 1994;23:773-783.

4 Rydel JJ, Korbet SM, Borok RZ, Schwartz MM: Focal segmental glomerular sclerosis in adults: presentation, course, and response to treatment. Am J Kidney Dis 1995:25:534542
5 Cattran DC, Rao P: Long-term outcome in children and adults with classic focal segmental glomerulosclerosis. Am J Kidney Dis 1998;32:72-79.

6 Ponticelli C, Villa M, Banfi G, Cesana B, Pozzi C, Pani A, Passerini P, Farina M, Grassi C, Baroli A: Can prolonged treatment improve the prognosis in adults with focal segmental glomerulosclerosis? Am J Kidney Dis 1999:34:618-625.

7 Stirling CM, Mathieson P, Boulton-Jones JM, Feehally J, Jayne D, Murray HM, Adu D: Treatment and outcome of adult patients with primary focal segmental glomerulosclerosis in five UK renal units. QJM 2005; 98:443-449.

8 Goumenos DS, Tsagalis G, El Nahas AM, Shortland JR, Davlouros P, Vlachojannis JG, Brown CB: Immunosuppressive treatment of idiopathic focal segmental glomerulosclerosis: A five-year follow-up study. Nephron Clin Pract 2006;104:c75-c82.

9 Usta M, Ersoy A, Dilek K, Ozdemir B, Yavuz M, Gullulu M, Yurtkuran M: Efficacy of losartan in patients with primary focal segmental glomerulosclerosis resistant to immunosuppressive treatment. J Intern Med 2003;253:329-334.
10 Korbet SM: Treatment of primary focal segmental glomerulosclerosis. Kidney Int 2002; 62:2301-2310.

11 Troyanov S, Wall CA, Miller JA, Scholey JW, Cattran DC: Toronto Glomerulonephritis Registry Group. Focal and segmental glomerulosclerosis: definition and relevance of a partial remission. J Am Soc Nephrol 2005; 16:1061-1068.

12 Segarra A, Vila J, Pou L, Majo J, Arbos A, Quiles T, Piera LL: Combined therapy of tacrolimus and corticosteroids in cyclosporinresistant or-dependent idiopathic focal glomerulosclerosis: a preliminary uncontrolled study with prospective follow-up. Nephrol Dial Transplant 2002;17:655-662.

13 Cattran DC, Wang MM, Appel G, Matalon A, Briggs W: Mycophenolate mofetil in the treatment of focal segmental glomerulosclerosis. Clin Nephrol 2004;62:405-411. 